\title{
Analise de trilha do teor de fósforo nos diferentes constituintes do milho irrigado
}

\author{
Path analysis of phosphorus content in different irrigated corn constituents \\ Análisis de ruta del contenido de fósforo en diferentes componentes del maíz de regadio
}

Recebido: 10/01/2022 | Revisado: 14/01/2022 | Aceito: 20/01/2022 | Publicado: 22/01/2022

Reginaldo Miranda de Oliveira
ORCID: https://orcid.org/0000-0002-1880-0730
Universidade Federal de Viçosa, Brasil
E-mail: reginaldo.miranda @ufv.br
Rubens Alves de Oliveira
ORCID: https://orcid.org/0000-0003-2557-592X
Universidade Federal de Viçosa, Brasil
E-mail: rubens@ ufv.br

Tulio Russino Castro

ORCID: https://orcid.org/0000-0002-1533-8587

Universidade Federal do Mato Grosso do Sul, Brasil

E-mail: rctulio@hotmail.com

Margareth Evangelista Botelho

ORCID: https://orcid.org/0000-0001-8746-2272

Universidade Federal de Viçosa, Brasil

E-mail: margareth.botelho@ufv.br

Raquel Dias Rodrigues

ORCID: https://orcid.org/0000-0002-6939-5931

Universidade Federal do Mato Grosso do Sul, Brasil

E-mail: raquel.dias.rodrigues@ hotmail.com

Gloria Milena Rojas Plazas

ORCID: https://orcid.org/0000-0001-7260-6712 Universidade Federal de Viçosa, Brasil

E-mail: gloria.plazas@ufv.br

Tayssa Menezes Franco

ORCID: https://orcid.org/0000-0001-5460-1360 Universidade Federal de Viçosa, Brasil

E-mail: tayssa.franco@ufv.br

Job Teixeira de Oliveira

ORCID: https://orcid.org/0000-0001-9046-0382

Universidade Federal do Mato Grosso do Sul, Brasil

E-mail: job.oliveira@hotmail.com

\begin{abstract}
Resumo
O milho nos tempos contemporâneos tornou-se o grão mais produzido no mundo. Portanto esse trabalho objetivou avaliar o efeito da absorção de fósforo nas características biométricas e produtivas da cultura do milho nas fases V6, V8, florescimento e colheita. Os atributos avaliados foram: teor de fósforo, massa fresca de folha no florescimento, massa fresca de caule no florescimento, massa seca de folha no florescimento, massa seca de caule no florescimento, massa seca do caule, massa fresca do caule, massa fresca da folha na colheita, massa seca da folha, massa fresca de folha em V6, massa seca de folha em V6, massa fresca de caule em V6, massa seca de caule em V6, massa seca de caule em V8, massa fresca de caule em V8, massa fresca de folha em V8, massa seca de folha em V8. Através da análise de trilha foi permitido estabelecer correlações entres estas variáveis que são indicativos de produtividade e qualidade do milho. Resultados mostram pela correlação de Pierson que massa fresca de caule e massa seca de caule nas diferentes fases estudadas, apresentam altos níveis de correlação positiva indicando que suas massas frescas e secas tendem, após testes e análises, ter proximidade de relações. Como conclusões, compreende-se que de maneira direta e positiva o fósforo obteve maior correlação com o peso médio de grãos. Efeito direto e negativo apenas massa fresca de folha no florescimento obteve resultados consideráveis em relação ao teor de fósforo.
\end{abstract}

Palavras-chave: Commodity; Zea mays; Estatística multivariada; Peso médio de grão.

\begin{abstract}
Corn in contemporary times has become the most produced grain in the world. Therefore, this work aimed to evaluate the effect of phosphorus absorption on the biometric and productive characteristics of corn in the V6, V8, flowering and harvest phases. The attributes evaluated were: phosphorus content, fresh leaf mass at flowering, stem fresh mass at flowering, leaf dry mass at flowering, stem dry mass at flowering, stem dry mass, stem fresh mass, fresh mass of leaf at harvest, leaf dry mass, leaf fresh mass in V6, leaf dry mass in V6, stem fresh mass in V6, stem dry mass in V6, stem
\end{abstract}


dry mass in V8, stem fresh mass in V8, fresh sheet mass in V8, dry sheet mass in V8. Through the path analysis, it was possible to establish correlations between these variables that are indicative of corn productivity and quality. Results show, by Pierson's correlation, that stem fresh mass and stem dry mass in the different phases studied, present high levels of positive correlation, indicating that their fresh and dry masses tend, after tests and analysis, to have close relationships. As conclusions, it is understood that in a direct and positive way phosphorus had a greater correlation with the average weight of grains. Direct and negative effect, only fresh leaf mass on flowering obtained considerable results in relation to phosphorus content.

Keywords: Commodity; Zea mays; Multivariate statistics; Mean grain weight.

\section{Resumen}

El maíz en la época contemporánea se ha convertido en el grano más producido en el mundo. Por tanto, este trabajo tuvo como objetivo evaluar el efecto de la absorción de fósforo sobre las características biométricas y productivas del maíz en las fases V6, V8, floración y cosecha. Los atributos evaluados fueron: contenido de fósforo, masa fresca de hoja a floración, masa fresca de tallo a floración, masa seca de hoja a floración, masa seca de tallo a floración, masa seca de tallo, masa fresca de tallo, masa fresca de hoja a cosecha, masa seca de hoja, masa fresca de hoja en V6, masa seca de hoja en V6, masa fresca de tallo en V6, masa seca de tallo en V6, masa seca de tallo en V8, masa fresca de tallo en V8, masa laminar fresca en V8, masa laminar seca en V8. A través del análisis de caminos, fue posible establecer correlaciones entre estas variables que son indicativas de la productividad y calidad del maíz. Los resultados muestran, por la correlación de Pierson, que la masa fresca del tallo y la masa seca del tallo en las diferentes fases estudiadas presentan altos niveles de correlación positiva, lo que indica que sus masas fresca y seca tienden, después de las pruebas y análisis, a tener relaciones cercanas. Como conclusiones se entiende que de manera directa y positiva el fósforo tuvo una mayor correlación con el peso promedio de los granos. Efecto directo y negativo, solo la masa foliar fresca en floración obtuvo resultados considerables en relación al contenido de fósforo.

Palabras clave: Producto; Zea mays; Estadísticas multivariadas; Peso medio del grano.

\section{Introdução}

O milho (Zea Mays) originário da América Central atualmente é cultivado mundialmente inclusive em boa parte do território brasileiro. Segundo Lima et al (2020), sua alta versatilidade com, atualmente, mais de 3000 derivados, explica sua importância social e econômica sendo denominado o grão mais produzido no mundo. A partir de 2020, o Brasil com mais de 72,9 milhões de toneladas de consumo interno e 35 milhões de toneladas exportadas acabou se realocando no ranking tornandose o terceiro maior produtor e o segundo maior exportador de milho no mundo (CONAB, 2021).

A demanda por alimento e por avanço de uma produção cada vez mais sustentável acaba gerando uma necessidade de aumento de produtividade de maneira mais coerente. Neste viés, são empregadas diversas pesquisas e práticas agrícolas para o progresso potencial da cultura, bem como o manejo adequado em irrigação e adubação. O milho apresenta necessidade e condições nutricionais adequadas, quantidade hídrica variável em decorrência do tipo de híbrido utilizado, do seu estádio fenológico, do espaçamento entre plantas, do índice de área foliar, e fitossanitárias da lavoura, além das características climáticas da região (Oliveira et al., 2021).

O desenvolvimento em todo o ciclo vegetal requer elementos minerais e orgânicos essenciais ao funcionamento metabólico, enzimático e estrutural das plantas. Nesta perspectiva, fornecer os nutrientes através do manejo adequado com doses ideais para cada tipo de substrato torna a adubação uma pratica fundamental visando o bom desenvolvimento das culturas e aumento da produtividade (Mumbach et al., 2017).

O fósforo, por base, é encontrado em moléculas de açúcares-fosfato, ácidos nucleicos, nucleotídeos, coenzimas, fosfolipídeos, ácido fítico, entre outros, possuindo função estrutural, no entanto, sua principal atividade está relacionada à transferência de energia pelas moléculas de ATP (Taiz et al., 2017). Por apresentar absorção principal via difusão e facilidade para sofrer imobilização, o fósforo reque altas doses de aplicação no solo, principalmente quando há deficiência histórica do nutriente na área, podendo ultrapassar a dosagem dos demais nutrientes, o que torna contraditório ao fato dele ser o menos exigido pelas plantas dentre os macronutrientes primários (Costa et al., 2012). A disponibilidade de fósforo em faixas ideais para as plantas promove o uso eficiente da água. 
É permitido por uma análise de trilha, compreender os efeitos diretos e indiretos de uma convergência entre uma variável principal e outras determinadas. A partir de uma compreensão técnica e estatística e por meio de um coeficiente de correlação entre as variáveis, são geradas estimativas que visam compreender melhor a relação entre os atributos. Segundo Verma et al (2020), essas mesmas se tornam úteis para identificar as características dos componentes que podem ser usados para melhorar a produtividade do milho. Portanto esse trabalho objetivou avaliar o efeito da absorção de fósforo nas características biométricas e produtivas da cultura do milho nas fases V6, V8, florescimento e colheita.

\section{Material e Métodos}

O presente estudo foi realizado no município de Coimbra - MG. nas dependências do Departamento de Fitotecnia da Universidade Federal de Viçosa (UFV) em sua área experimental, no período da safra 2017/2018. O local do experimento está situado na mesorregião da Zona da Mata, situado nas seguintes coordenadas geográficas $20^{\circ} 49^{\prime} 51$ ' de latitude Sul e 42 $48^{\prime} 10^{\prime \prime}$ de longitude Oeste, com altitude de $716 \mathrm{~m}$. A região possui clima tropical de altitude (Cwb), segundo a classificação de Köppen, com período altamente chuvoso, principalmente nos meses de dezembro e janeiro, alcançando média anual de precipitação de $1.300 \mathrm{~mm}$ e temperatura média anual de $19^{\circ} \mathrm{C}$.

Com uso de um trado holandês foram retiradas amostras de solo na camada de 0 a 0,20 m de profundidade antes do plantio para a sua caracterização física e química. Deste modo, ele foi classificado, segundo Santos et al. (2018), como Argissolo Vermelho Amarelo Distrófico, argiloso/argiloso com relevo suave ondulado, caulinítico (PVAd). Sua capacidade de campo (Cc) e o ponto de murcha permanente $(\mathrm{Pm})$ foram medidos usando-se o Extrator de Richards. A pratica ocorreu no Laboratório de Física do Solo do Departamento de Engenharia Agrícola da Universidade Federal de Viçosa (UFV).

A densidade do solo foi determinada pelo método do tubo de PVC. As porcentagens de argila, silte e areia grossa foram de $58 \%, 18 \%$ e $24 \%$, respectivamente. O teor de água na capacidade de campo foi de 0,335 gramas por grama de solo $\left(\mathrm{g} \mathrm{g}^{-1}\right) \mathrm{e}$ no ponto de murcha permanente de $0,180\left(\mathrm{~g} \mathrm{~g}^{-1}\right)$. A densidade do solo foi de $1,300 \mathrm{~g} \mathrm{~cm}^{-3}$.

A disponibilidade de fósforo no solo também foi avaliada. As amostras foram retiradas momentos antes do plantio, e analisadas no Laboratório de Fertilidade do Solo do Departamento de Solos da UFV, de acordo com metodologias descritas por Teixeira et al (2017).

O sistema de cultivo adotado foi o plantio direto, posteriormente foi realizada uma adubação com superfosfato triplo (46\% de P2O5) de acordo com os tratamentos testados. A adubação com nitrogênio e potássio foram feitas em duas aplicações em cobertura, quando as plantas de milho se encontravam nos estádios fenológicos V3 e V6, apresentando três e seis folhas totalmente formadas, respectivamente.

O híbrido de milho utilizado no plantio foi o DKB 390 PRO-III, híbrido simples, de ciclo precoce, com arquitetura foliar semi-ereta, com altura média de plantas variando de 2,25 a 2,45 m, a altura de inserção de espiga de 1,25 a 1,40 m, boa tolerância a elevadas temperaturas, ampla adaptação a diferentes tipos de solo e manejo e com finalidade de produção de grãos.

Durante todo ciclo da cultura estudada até sua colheita, alguns atributos foram determinados para o presente estudo, sendo eles descritos abaixo:

- O teor de fósforo (P): obtido considerando-se a quantidade de fósforo, em $\mathrm{mg} \mathrm{dm}^{-3}$, já existente no solo na camada de 0 a $0,20 \mathrm{~m}$, fornecida pela análise de solo, mais a quantidade de $\mathrm{P}$ suprida via fertilizante.

-Peso médio de grãos (PMG): Foi realizada colheita manual de todas as espigas de cada unidade experimental. Posteriormente, foi realizada a debulha e a determinação da umidade dos grãos utilizando medidores de bancada da Gehaka. A pesagem de grãos corrigida para teor de água equivalente a 13\%, utilizando-se da Equação 7 e, assim determinando a produtividade em $\mathrm{kg} \mathrm{ha}^{-1}$. 


$$
P M G=P *\left[\frac{1-\left(\frac{U}{100}\right)}{0,87}\right]
$$

em que: $\mathrm{PMG}=$ peso médio de grãos corrigida para a umidade padrão de $13 \%, \mathrm{~g}, \mathrm{P}=$ peso médio de grãos após a colheita, $\mathrm{g}$, $\mathrm{e}$ $\mathrm{U}=$ umidade dos grãos após a colheita, \%.

Foi determinado o peso de 1.000 grãos $\left(\mathrm{P}_{1000}\right)$ corrigido para o teor de umidade a $13 \%$ com uso de uma balança digital com precisão de $0,01 \mathrm{~g}$.

Seguindo o procedimento descrito por Malavolta et al. (1997), alguns desses atributos foram seccionados a partir dos estádios fenológicos presentes durante o desenvolvimento da cultura, sendo eles:

-Na fase V6: foram retiradas, no decorrente estádio fenológico, uma planta de cada unidade experimental respectivamente. Após cortadas rente ao chão as massas relativas das partes constituintes, foram determinadas, sendo estas massa fresca de folha na fase V6 (FF6) e massa fresca de caule na fase V6 (FC6). Posteriormente o material foi seco em estufa de circulação de ar à $65{ }^{\circ} \mathrm{C}$, até a obtenção de massa constante medida com uma balança analítica de precisão $(0,01 \mathrm{~g})$. Consequentemente foram determinadas massa seca de folha na fase V6 (SF6) e massa seca de caule na fase V6 (SC6).

-Na fase V8: O processo é similar ao anterior. Foram retiradas, no decorrente estádio fenológico, uma planta de cada unidade experimental respectivamente. Após cortadas rente ao chão as massas relativas das partes constituintes foram determinadas, sendo estas, massa fresca de folha na fase V8 (FF8) e massa fresca de caule na fase V8 (FC8). Posteriormente o material foi seco em estufa de circulação de ar à $65^{\circ} \mathrm{C}$, até a obtenção de massa constante medida com uma balança analítica de precisão $(0,01 \mathrm{~g})$. Consequentemente foram determinadas massa seca de folha na fase V8 (SF8) e massa seca de caule na fase V8 (SC8).

-No estádio de florescimento e colheita uma planta de cada unidade experimental foi cortada rente ao solo, respectivamente. Em seguida as massas das partes constituintes foram determinadas sendo: massa fresca de folha no florescimento (FFF), massa fresca de caule no florescimento (FCF), massa fresca de folha na colheita (MFF) e massa fresca de caule na colheita (MFC). Posteriormente esse material foi seco em estufa de circulação de ar à $65^{\circ} \mathrm{C}$ até a obtenção da massa constante aferida com uma balança analítica de precisão $(0,01 \mathrm{~g})$. Dessa forma foram determinados a massa seca de folha no florescimento (SFF), massa seca de caule no florescimento (SCF), massa seca da folha na colheita (MDF) e massa seca de caule na colheita (MSC).

A rede de correlações juntamente com os atributos estudados foi gerada por intermédio do Software RBio, Bhering (2017). A análise de trilha usada neste trabalho utilizou o Software GENES (Cruz, 2013) para buscar uma associação das relações entres diferentes variáveis, excluindo possíveis multicolinearidade e atingindo sua eficiência.

\section{Resultados e discussão}

A Figura 1 mostra a rede de correlações entre os atributos estudados, com relações positivas destacadas em verde e negativas destacadas em vermelho. Vale ressaltar que a espessura da linha é afetada pelo maior grau de correlação, ou seja, quanto mais espessa a linha maior a correlação entre os atributos. As estimativas obtidas a partir da matriz de correlações, oscilaram entre -0.249 a 0.902 . 
Figura 1 - Rede de correlação dos atributos estudados: Fósforo (P), massa fresca de folha no florescimento (FFF), massa fresca de caule no florescimento (FCF), massa seca de folha no florescimento (SFF), massa seca de caule no florescimento (SCF), massa seca do caule na colheita (MSC), massa fresca do caule na colheita (MFC), massa fresca da folha na colheita (MFF), massa seca da folha na colheita (MDF), massa fresca de folha em V6 (FF6), massa seca de folha em V6 (SF6), massa fresca de caule em V6 (FC6), massa seca de caule em V6 (SC6), massa seca de caule em V8 (SC8), massa fresca de caule em V8 (FC8), massa fresca de folha em V8 (FF8), massa seca de folha em V8 (SF8) e peso médio dos grãos (PMG).

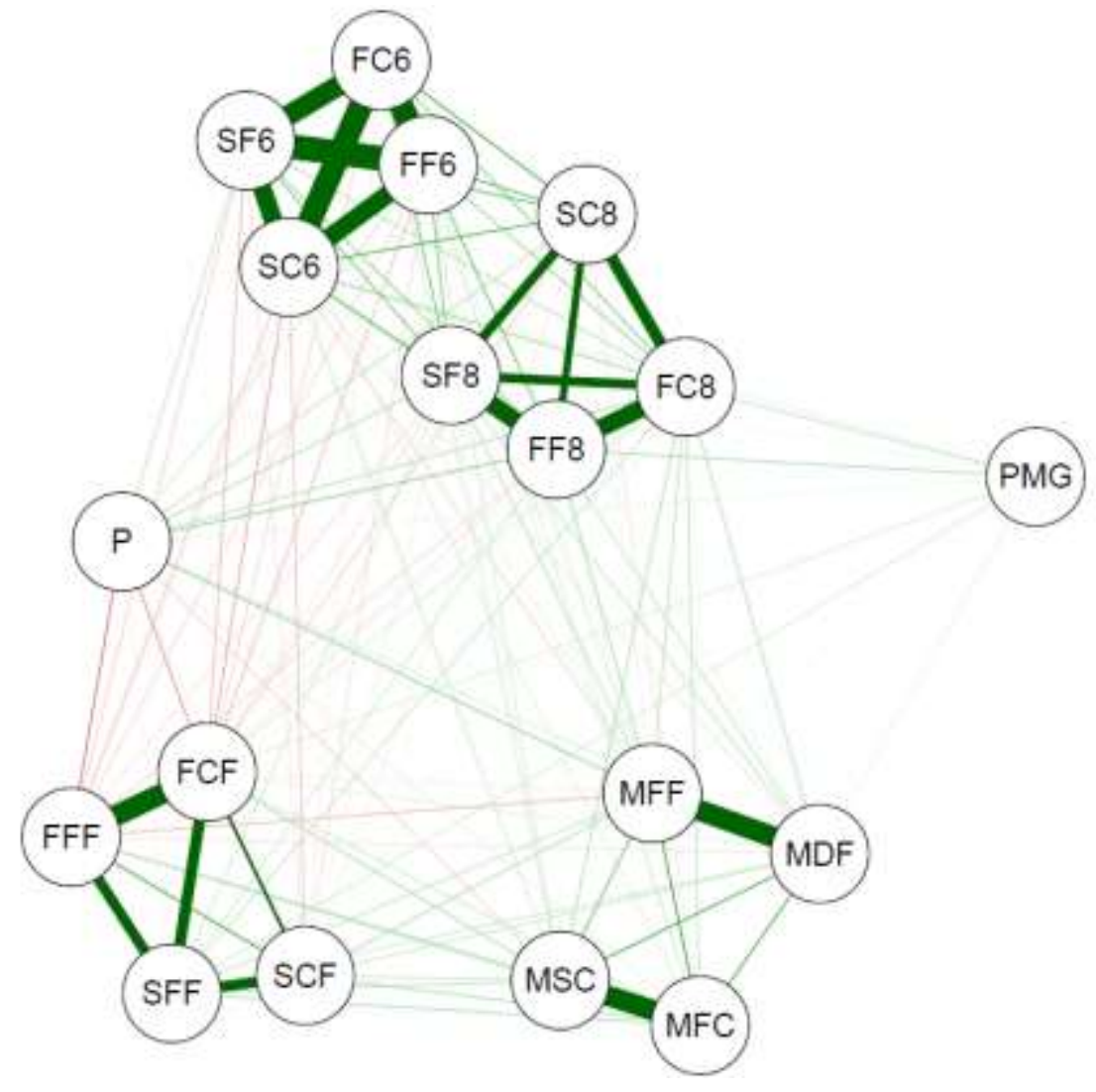

Fonte: Autores.

Analisando a Figura 1, observa-se que FC6 e SC6 assim como FF6 e SF6 e MFF e MSF apresentam altos níveis de correlação positive indicando que suas massas frescas e secas tendem, após testes e análises, ter proximidade de relações. Dessa forma ambas relações tendem a ser grandezas diretamente proporcionais. Estas mesmas correlações positivas, são verificadas nas demais fases do estudo, sendo elas V8, Florescimento e colheita, indicando que aumento de massa fresca implica em aumento de massa seca durante os estágios de desenvolvimento da cultura do milho.

Notoriamente a partir dessas fortes ligações compreende-se que tais atributos atuam de forma direta para um bom desenvolvimento de espiga e elevação na produtividade. De acordo com Grant et al. (2001), geralmente, a falta de P diminui o número de espigas férteis e de grãos por espiga, resultando em menor produtividade de grãos. Sendo assim a antípoda também é coerente.

A partir da relação de FCF com FF6, SC6 e SF6 obtém resultados negativos aparentes em ambos. Compreende-se dessa maneira que todos os atributos do estágio de V6 de folha e caule se diferem com os resultados obtidos no florescimento, em específico, no caule.

Para a análise de trilha, o teor de fósforo foi utilizado como a variável principal correlacionado, de maneira direta quanto indireta com os demais atributos do estudo. Para que seja proporcionado um resultado dinamizado com os demais, por conseguinte, torna-se importante a possibilidade de uma aproximação dos dados imparciais com a real situação de campo. A Figura 2 ilustra os resultados da análise. 
Figura 2 - Analise de trilha entre o teor de fosfato (P) como variável principal e demais atributos: massa fresca de folha em V6 (FF6), massa seca de folha em V6 (SF6), massa fresca de caule em V6 (FC6), massa seca de caule em V6 (SC6), massa fresca de folha em V8 (FF8), massa seca de folha em V8 (SF8), massa fresca de caule em V8 (FC8), massa seca de caule em V8 (SC8), massa fresca de folha no flore scimento (FFF), massa seca de folha no florescimento (SFF), massa fresca de caule no florescimento (FCF), massa seca de caule no florescimento (SCF), massa fresca da folha na colheita (MFF), massa seca da folha na colheita (MDF), massa fresca do caule na colheita (MFC), massa seca do caule na colheita (MSC), peso médio de grãos (PMG).
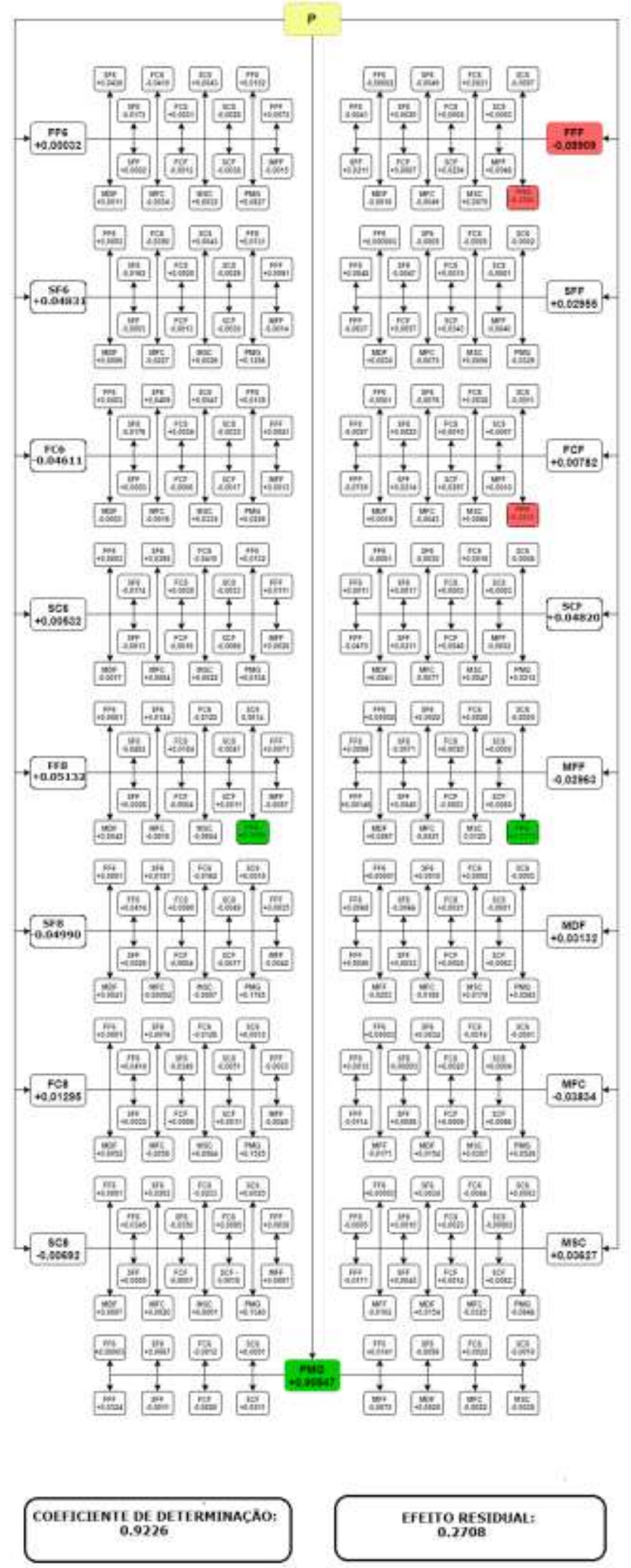

Fonte: Autores. 
Na Figura 2 podemos constatar que de forma direta, a análise de trilha possibilitou apurar que o teor de fósforo (P) influencia PMG de forma positiva e significativa com valor de 0.90547. Araújo et al (2003), descreve que elevados valores de $\mathrm{P}$ acumulado no grão, revelam que fatores intrínsecos ou não ao híbrido foram condicionantes restritivos para que o $\mathrm{P}$ adicionalmente absorvido e direcionado aos grãos resultasse em ganho de produtividade.

$\mathrm{O}$ teor de fósforo $(\mathrm{P})$ apresentou de forma negativa, uma correlação com massa fresca de folha no florescimento (FFF) com valor de -0.089. Esta correlação negativa corrobora com Menezes et al (2018) aonde descreve que o maior acúmulo de fósforo ocorre no período reprodutivo, próximo da época de pendoamento da planta de milho.

Verificando de forma indireta a análise de trilha nota-se que, de maneira significativa e positiva FF8 e MFF com seus respectivos coeficientes de correlação: 0.2480 e 0.2301 influenciaram PMG. Em contrapartida de maneira negativa e ainda significativa FFC e FFF com seus devidos coeficientes: -0.2343 e -0.392, também influenciaram o PMG. Segundo Prado et al (2001) O aumento do teor foliar de fósforo, considerando a adubação fosfatada localizada, pode explicar o aumento da produção de grãos, tendo em vista a relação positiva entre o teor foliar de $\mathrm{P}$ e a produção de grãos.

Compreende-se pelos dados coletados, um descolamento dos níveis de fósforo $(\mathrm{P})$ das partes analisadas relativas a massa de caule e folha em estágio inicial e final do desenvolvimento vegetativo da planta até as partes analisadas referente ao começo do estágio germinativo, no caso florescimento. Como o fósforo pode ser interpretado como uma moeda energética para a planta seu deslocamento por ela é justificado pela fase e área que está em maior atividade metabólica para desenvolvimento e sobrevivência. Marschner (2012) descreve as funções que este nutriente exerce nas plantas, tais como componentes dos fosfolipídios, ATP, DNA, RNA, açúcares fosfatos e outras moléculas fundamentais no crescimento dos vegetais e neste caso o desenvolvimento dos grãos.

O coeficiente de determinação neste estudo foi de 0.9226 que pelo seu alto coeficiente pode ser agregado em próximas melhorias e desenvolvimento para a cultura do milho grão. Cultura muito importante em todo o mundo. Oliveira et al, (2020), e Silva Pinheiro et al, (2021), destacam que valores de coeficiente de determinação superiores a 0,7500 em estudo com atributos físicos via análise de trilha são considerados altos. Pinheiro et al. (2021), encontraram coeficiente de determinação de 0,7544 em estudo com atributos físicos do milho via análise de trilha, indicando que o valor encontrado no presente estudo é muito satisfatório.

\section{Considerações Finais}

De forma direta, a análise de trilha possibilitou verificar que o teor de fósforo é a variável que melhor se correlaciona, positivamente, com o peso médio de grãos.

A massa fresca de folha no florescimento apresenta correlação direta e negativa, com peso médio de grãos.

Indiretamente observamos pela análise de trilha, que massa fresca de folha em V8 e massa fresca de folha na colheita tem correlação positiva com o peso médio de grãos e massa fresca de caule no florescimento. Massa fresca de folha no florescimento apresentaram correlação negativa com peso médio de grãos de forma indireta.

\section{Agradecimentos}

À Universidade Federal de Viçosa, UFV e à Universidade Federal do Mato Grosso do Sul, CPCS-UFMS.

\section{Referências}

Araújo, I. B., Resende, A. V., Furtini Neto, A. E., Alves, V. M. C., \& Santos, J. Z. L. (2003). Eficiência nutricional do milho em resposta a fontes e modos de aplicação de fósforo. Embrapa Milho $e$ Sorgo - Artigo em em https://ainfo.cnptia.embrapa.br/digital/bitstream/item/52851/1/Eficiencia-nutricional.pdf. 
Bhering, L. L. (2017). Rbio: A Tool For Biometric And Statistical Analysis Using The R Platform. Crop Breeding and Applied Biotechnology, 17: 187-190p. https://doi.org/10.1590/1984-70332017v17n2s29.

Cruz, C.D. Genes: (2013). A Software Package for Analysis in Experimental Statistics and Quantitative Genetics. Acta Scientiarum: Agronomy, 35,271 - 276. https://doi.org/10.4025/actasciagron.v35i3.21251.

CONAB. (2021). Acompanhamento da Safra Brasileira de Grãos, v. 8 Safra 2020/21, n.6 - Sexto levantamento, Brasília, p. 1-106, março 2021. https://www.conab.gov.br/info-agro/safras/graos/boletim-da-safra-de-graos.

Costa, M. S., Costa, Z. B. B., Alves, S. M. C., Neto, M. F., \& Marinho, M. J. C. (2012). Avaliação nutricional do milho cultivado com diferentes doses de efluente doméstico tratado. Irriga, Botucatu, Edição Especial, 12 - 26, https://doi.org/10.15809/irriga.2012v1n01p12.

Grant, C. A., Flaten, D. N., Tomasiewicz, D. J., \& Sheppard, S. C. (2001). A importância do fósforo no desenvolvimento inicial da planta: Encarte de informações agronômicas $\quad$ n. $\quad 95 . \quad$ Piracicaba: $\quad$ Potafos, $\quad$ http://www.ipni.net/publication/iabrasil.nsf/0/B70BBB24C44D200283257AA30063CAA6/\%24FILE/Jornal\%2095.pdf.

Lima, B. C., Dudek, G., Chaves, M. H. M., Martins, A. G., Missio, V. C., \& Missio, R. F. (2020). Diversidade genética em acessos de milho crioulo. Brazilian Journal of Development, 6(10), 82712-82726, https://doi.org/10.34117/bjdv6n10-631.

Malavolta, E., Vitti, G. C., \& Oliveira, S. A. (1997). Avaliação do estado nutricional de plantas: princípios e aplicações. Piracicaba: Potafos, 319 p. CDD 581 13. https://repositorio.usp.br/item/001070906.

Marschner, H. (2012). Mineral nutrition of higher plants. School of agriculture. London: Elsevier. 650 p.

Menezes, J. F. S., Berti, M. P. S., Vieira Junior, V. D., Ribeiro, R. L., \& Berti, C. L. F. (2018). Extração e exportação de nitrogênio, fósforo e potássio pelo milho adubado com dejetos de suínos. Revista de Agricultura Neotropical, 5(3), 55-59. https://periodicosonline.uems.br/index.php/agrineo/article/view/1645/2335.

Mumbach, G. L., Kotowski, F. J. A., Schneider, M. S., Mallmann, E. B., Bonfada, V. O., Portela, E. B., \& Bonfada, D. R. K. (2017). Resposta da inoculação com Azospirillum brasilense nas culturas de trigo e de milho safrinha. Revista Scientia Agraria, 18:97-103. http://dx.doi.org/10.5380/rsa.v18i2.51475.

Oliveira, R. M., Oliveira, R. A., Botelho, M. E., Galvão, J. C. C., Niero, M. E. S., \& Oliveira, J. T. (2021). Efeito Da Frequência De Irrigação Na Absorção De Fósforo Na Produção Do Milho. Revista Ibero-Americana de Ciências Ambientais, 12(5). https://sustenere.co/index.php/rica/article/view/5440.

Oliveira, J. T., Oliveira, R. A., Oliveira, L. A. A., Teodoro, P., \& Montanari, R. (2020). Spatial variability of irrigated garlic (Allium sativum L.) production components. HortScience, 55(3), 300-303. https://doi.org/10.21273/HORTSCI14409-19.

Pinheiro, L.S., Silva, R. C., Vieira, R.C., Aguiar, R. O., Nascimento, M. R., Vieira, M. M., \& Silva, P. A. (2021). Análise de trilha dos atributos físicos de milho (Zea mays L.) em sistema de cultivo convencional. Research, Society and Development, 10 (1). https://doi.org/10.33448/rsd-v10i1.10832.

Prado, R. M., Fernandes, F. M., \& Roque, C. G. (2001). Resposta da cultura do milho a modos de aplicação e doses de fósforo, em adubação de manutenção. Revista Brasileira de Ciência do Solo, 25(1), 83-90, https://doi.org/10.1590/S0100-06832001000100009.

Santos, H. G., Jacomine, P. K. T., Anjos, L. H. C., Oliveira, V. A., Lumbreras, J. F., Coelho, M. R., \& Cunha, T. J. F. (2018). Sistema brasileiro de classificação de solos.: Embrapa.

Silva Pinheiro, L., Silva, R. C., Conceição Vieira, R., Aguiar, R. O., Nascimento, M. R., Vieira, M. M., Oliveira, J. T., \& Silva, P. A. (2021). Análise de trilha dos atributos físicos de milho (Zea mays L.) em sistema de cultivo convencional. Research, Society and Development, 10(1), e8010110832-e8010110832. https://doi.org/10.33448/rsd-v10i1.10832.

Taiz, L., Zeiger, E., Møller, I. M., \& Murphy, A. (2017). Fisiologia e desenvolvimento vegetal. 6. ed. Porto Alegre: Editora Artmed, 858 p.

Teixeira, P. C., Donagemma, G. K., Fontana, A., \& Teixeira, W. G. (2017). Manual de métodos de análise de solo. Brasília: Embrapa, 573.

Verma, V., Yadav, M. S., Kumar, A., \& Gathiye, G. S. (2020). Correlation and path analysis for seed yield and components traits in maize (Zea mays L.). Journal of Pharmacognosy and Phytochemistry, 9(1), 2278-2280. https://www.phytojournal.com/archives/2020/vol9issue1/PartAL/9-1-476-770.pdf. 